\title{
ANALISIS CODE SWITCHING DALAM SEMINAR PROPOSAL PROGRAM STUDI PENDIDIKAN BAHASA INGGRIS STKIP BUDIDAYA BINJAI
}

\author{
Rakhmat Wahyudin Sagala ${ }^{1)}$, Tri Indah Rezeki ${ }^{2)}$ \\ Program Studi Pendidikan Bahasa Inggris, Universitas Muhammadiyah Sumatera Utara ${ }^{1)}$ \\ rakhmatwahyudin@umsu.ac.id \\ Program Studi Pendidikan Bahasa Inggris, STKIP Budidaya Binjai ${ }^{2)}$ \\ triindahrizky@yahoo.com ${ }^{2}$
}

\begin{abstract}
ABSTRAK
Dosen dan mahasiswa Program Studi Pendidikan Bahasa Inggris notabenenya harus menggunakan bahasa Inggris didalam proses kegiatan yang berhubungan dengan Program Studi Pendidikan Bahasa Inggris. Faktanya, terbatasnya penggunaan bahasa Inggris membuat mahasiswa sering menggunakan code switching dalam kegiatan yang berhubungan dengan Program Studi Pendidikan bahasa Inggris. Studi ini bertujuan untuk mengetahui fenomena code switching yang terjadi didalam proses seminar proposal Prodi Bahasa Inggris Sekolah Tinggi Keguruan dan Ilmu Pendidikan (STKIP) Budidaya Binjai. Penelitian deskriptif kualitatif ini mengambil data dari proses seminar proposal Program Studi Pendidikan Bahasa Inggris yang mana dosen penguji dan mahasiswa peserta seminar sebagai subjek penelitian dan data diperoleh melalui observasi, wawancara, rekaman dengan menggunakan rekaman video dan catatan lapangan. Dari hasil temuan disimpulkan bahwa code switching terjadi dalam tuturan selama proses seminar proposal prodi Bahasa Inggris. Jenis code switching yang terdapat dalam tuturan berdasarkan teori Romaine (2000) yaitu Inter-sentential code switching, Intra-sentential code switching dan Tag switching. Faktor dosen dan mahasiswa melakukan code switching adalah karena perubahan situasi karena hadirnya orang ketiga, perubahan situasi dari formal ke informal atau sebaliknya, dan berubahnya topik pembicaraan. Dari hasil interview juga disimpulkan bahwa mahasiswa melakukan code switching karena bahasa Inggris bukan bahasa pertama mereka sehingga kurangnya kosakata bahasa Inggris membuat mereka sering menggunakan code switching didalam percakapannya. Penelitian ini dibiayai oleh SIMLITABMAS. Direktorat Riset dan Pengabdian Masyarakat. Direktorat Jenderal Penguatan Riset dan Pengembangan. Kementerian Riset, Teknologi dan Pendidikan Tinggi, sesuai dengan kontrak penelitian tahun anggaran 2018.
\end{abstract}

Kata Kunci: Code Switching, Jenis Code Switching, Faktor Code Switching

\section{Pengantar}

Bahasa merupakan bagian terpenting dalam kehidupan manusia untuk berkomunikasi dengan yang lainnya. Ketika bahasa yang digunakan seseorang dalam menyampaikan pesan dirasakan kurang berhasil atau gagal, orang tersebut perlu merubah bahasanya dengan bahasa yang dipahami (Rezeki, 2018). Masyarakat yang memiliki kemampuan menggunakan satu bahasa atau lebih disebut sebagai bilingual atau multilingual, sangat mungkin bagi mereka untuk mengganti bahasa yang mereka gunakan ketika sedang berbahasa atau berbicara. Fenomena seperti ini dikenal dengan code-switching. Code-switching dapat terjadi karena bahasa adalah salah satu bentuk simbol perilaku manusia yang paling penting dan merupakan komponen penting dalam identitas sebuah kelompok. Ada tiga jenis pilihan bahasa yang dikenal dalam kajian sosiolinguistik, yaitu alih kode (code switching), campur kode (mixing code) dan variasi dalam bahasa yang sama (variation within the same language) Sumarsono (2004:201).

Umumnya dalam lingkungan pendidikan, termasuk di Perguruan Tinggi, hal ini mungkin dilakukan oleh guru atau dosen dan siswa untuk mengubah bahasanya karena mereka berbicara dengan lebih dari satu bahasa. When the speaker cannot convey his/her message by using one language, the speaker needs to change the language to be more understood (Sagala, 2018). Dalam hal ini code switching terjadi di dalam proses seminar proposal Program Studi Pendidikan Bahasa Inggris STKIP Budidaya Binjai ketika 
mereka sedang berinteraksi. Mereka dapat mengganti atau mencampur bahasanya ketika mempunyai persepsi yang sama terhadap hal atau sesuatu yang sedang dikomunikasikan.

Di jurusan Pendidikan Bahasa dan Sastra Inggris, hampir semua kelas yang merupakan mata kuliah keterampilan diajarkan dengan menggunakan Bahasa Inggris sebagai medium interaksinya. Hal ini bertujuan agar dosen dan mahasiswa terbiasa dengan Bahasa Inggris didalam proses perkuliahan. Baik dosen maupun mahasiswa sering mengganti bahasa mereka pada bagianbagian tertentu dan kemudian kembali pada bahasa awalnya lagi. Mereka juga kadang benar-benar berganti bahasa secara menyeluruh. Seorang dosen cenderung mengganti bahasa yang digunakan untuk memperjelas informasi yang disampaikan. Sementara mahasiswa cenderung mengganti bahasa yang mereka gunakan karena kurangnya pengetahuan mereka tentang bahasa yang mereka gunakan.

Alih kode (code switching) adalah gejala pemakaian bahasa karena berubahnya situasi (Appel dalam Chaer dan Agustina, 2010: 107). Hymes (dalam Chaer dan Agustina, 2010: 107) menyatakan bahwa alih kode adalah gejala peralihan bahasa yang bukan hanya terjadi antar bahasa, tetapi dapat juga terjadi antar ragam-ragam atau gaya-gaya yang terdapat dalam satu bahasa. Misalnya peralihan dari bahasa Indonesia ke bahasa asing, seperti bahasa Inggris. Sejalan dengan hal tersebut, A Chaedar (1998: 66) memberikan penjelasan mengenai alih kode yang dikatakan sebagai bentuk peralihan dari satu dialek ke dialek lainnya. Nababan (1991: 6) juga menyatakan bahwa alih kode terjadi jika keadaan berbahasa itu menuntut penutur mengganti bahasa atau ragam bahasa yang sedang dipakai. Terlebih lagi, Harimurti (2011: 7) mendefinisikan secara singkat bahwa alih kode sebagai penggunaan variasi bahasa lain untuk menyesuaikan diri dengan peran atau situasi lain. Alih kode merupakan kemampuan untuk beralih dari kode $\mathrm{A}$ ke kode $\mathrm{B}$, atau disebut juga peralihan dari satu bahasa ke bahasa yang lain (Kachru dalam Rahmadani, 2011: 107). Pergantian kode ini ditentukan oleh fungsi, situasi, dan partisipan. Dengan kata lain, alih kode mengacu pada kategori dari khazanah verbal seseorang dalam hal fungsi dan peran.

Berdasarkan definisi yang dipaparkan para ahli tersebut, maka yang dimaksud code switching adalah pergantian bahasa dari satu bahasa tertentu ke bahasa lain atau berubahnya ragam santai menjadi resmi atau sebaliknya, pengalihan itu dilakukan oleh seseorang dalam keadaan sadar karena sebab-sebab tertentu.

Dalam gambaran faktor-faktor code switching penulis mengacu pada teori dari Chaer dan Agustina (2010) penyebab terjadinya code switching sebagai berikut: 1) Pembicara atau penutur, 2) Pendengar atau lawan tutur, 3) Perubahan situasi karena hadirnya orang ketiga, 4) Perubahan situasi dari formal ke informal atau sebaliknya, 5) Berubahnya topik Pembicaraan.

Romaine (2000) membedakan 3 jenis Code Switching yaitu Inter Sentential Code Switching, Intra Sentential Code Switching, dan Tag Code Switching. Inter Sentential terjadi diantara kalimat. Misalnya, "What is your research design. Jelaskan apa desain penelitian kamu?". Intra Sentential Code Switching terjadi dipertengahan kalimat. Misalnya, "Well, apa research problem kamu?". Sedangkan Tag Code switching terjadi ketika bilingual memasukkan ungkapan pendek dari Bahasa yang berbeda pada akhir ucapannya atau terjadi dalam kalimat tanda seru. Misalnya, "Penelitian yang marvelous!" atau "It's ok, no problem, yang nggak?"

Penelitian ini mendeskripsikan codeswitching yang terjadi di dalam proses seminar proposal Program Studi Pendidikan Bahasa Inggris Sekolah Tinggi Keguruan dan Ilmu Pendidikan (STKIP) Budidaya Binjai, jenis-jenis code switching yang digunakan menurut teori Romaine (2000) dan faktor-faktor yang menyebabkan terjadinya code switching menurut teori Chaer dan Agustina (2010).

Dalam penelitian ini yang diteliti adalah bentuk tuturan atau percakapan antara dosen dan mahasiswa selama proses seminar proposal yang terdapat code switching didalamnya, maka penyajiannya dimulai dari analisis percakapan lalu dikaitkan dengan teori code switching. Dari hasil analisis data terdapat jenis code switching didalam percakapan antara dosen dan mahasiswa selama proses seminar yaitu Inter-sentential code switching, Intra-sentetial code switching dan Tag code switching. Lebih lanjut peneliti melakukan interview kepada para informan yakni dosen dan mahasiswa untuk mengetahui faktor mengapa mereka melakukan code switching dan alasannya adalah karena perubahan situasi karena hadirnya orang ketiga, perubahan dari situasi formal ke situasi informal, dan berubahnya topik pembicaraan. 


\section{Pembahasan}

\subsection{Subjek Penelitian}

Subjek penelitian atau informan adalah dosen Program Studi Pendidikan Bahasa Inggris sebagai dosen penguji dalam seminar proposal dan mahasiswa Program Studi Pendidikan Bahasa Inggris sebagai peserta dalam seminar proposal.

\subsection{Desain Penelitian}

Penelitian adalah deskriptif kualitatif mengacu pada teori Miles dan Huberman (1992) dan Moleong (2012) yaitu prosedur penelitian yang menghasilkan data deskriptif berupa kata-kata tertulis atau lisan dari orang-orang dan perilaku yang diamati. Adapaun data yang akan diperoleh dari penelitian berupa jenis code switching serta faktor-faktor penyebab terjadinya code switching dalam tuturan pada seminar proposal Program Studi Pendidikan Bahasa Inggris STKIP Budidaya Binjai.

\subsection{Pengumpulan Data dan Teknik Analisis}

Dalam penelitian ini yang menjadi instrumen penelitian adalah peneliti sendiri (Sugiyono, 2008:8). Peneliti melakukan validasi sebelum terjun ke lapangan penelitian dengan melakukan persiapan meliputi pemahaman metode penelitian kualitatif deskriptif dan penguasaan teori mengenai objek yang diteliti yaitu analisis Code Switching dalam seminar proposal Prodi Pendidikan Bahasa Inggris. Dalam mengumpulkan data, peneliti menggunakan alat bantu berupa pedoman wawancara, pedoman observasi, buku catatan dan alat perekam untuk memudahkan peneliti dalam melakukan pengumpulan data. Teknik yang digunakan untuk mengumpulkan data dalam penelitian ini adalah dengan wawancara, observasi dan dokumentasi.

\subsection{Analisis Data}

Setelah mengumpulkan dan mentranskip data bagaimana dosen penguji dan mahasiswa peserta seminar proposal menggunakan alih kode dari satu bahasa ke bahasa lain. Bahasa yang digunakan adalah bahasa Inggris dan bahasa Indonesia. Jenis code switching dianalisis berdasarkan teori Romaine (2000) yaitu Inter sentential code switching, Intra sentential code switching, and tag code switching. Dari data diperoleh:
Tabel 2.1. Hasil Analisis Data

\begin{tabular}{cccc}
\hline \multirow{2}{*}{$\begin{array}{c}\text { Jadwal } \\
\text { Peminar }\end{array}$} & \multicolumn{2}{c}{ Jenis-jenis Code Switching } \\
\cline { 2 - 4 } & $\begin{array}{c}\text { Intra } \\
\text { Sentential } \\
\text { Code } \\
\text { Switching }\end{array}$ & $\begin{array}{c}\text { Inter } \\
\text { Sentential } \\
\text { Code } \\
\text { Switching }\end{array}$ & $\begin{array}{c}\text { Tag Code } \\
\text { Switching }\end{array}$ \\
\hline $\begin{array}{c}\text { 19 Maret } \\
\text { 2018 }\end{array}$ & 49 & 33 & 10 \\
\hline TOTAL & 49 & 33 & 10 \\
\hline
\end{tabular}

Table 2.1 menunjukkan bahwa terdapat 42 tuturan yang berisi Intra sentential code switching, 26 tuturan yang berisi Inter sentential code switching, dan 19 tuturan yang berisi Tag code switching. Berikut adalah contoh percakapan hasil analisis data:

\section{Data 1}

Dosen : "Well, apa research problem kamu?"

Mahasiswa : "My research problem is untuk mencari pengaruh Semantic Mapping terhadap writing descriptive"

Dari percakapan diatas dianalisis bahwa penutur menggunakan jenis Intra-sentential code switching yaitu alih kode terjadi dipertengahan kalimat. Penutur merubah bahasa Inggris ke bahasa Indonesia dan kembali lagi menggunakan bahasa Inggris. Dari interview dosen tersebut menggunakan code switching untuk memudahkan mahasiswa mengerti maksud pertanyaan penguji. Sedangkan mahasiswa menggunakan code switching karena tidak mengetahui bahasa target yaitu bahasa Inggris.

\section{Data 2}

Dosen : "Apa kamu yakin? Do you think that multiple choice suitable to

comprehension? measure students' reading

Mahasiswa : "I think yes mom. Karena yang mau dilihat kemampuan reading"

Dari percakapan diatas dianalisis bahwa penutur menggunakan jenis Intra-sentential code switching yaitu alih kode terjadi diantara kalimat. Dosen menggunakan kalimat pertama bahasa Indonesia kemudian kalimat kedua menggunakan bahasa Inggris. Dari interview dosen menggunakan code switching karena perubahan situasi dari 
informal ke formal. Pernyataan "Apa kamu yakin" merupakan informal kemudian kembali menggunakan bahasa Inggris untuk situasi formal. Sedangkan mahasiswa menggunakan kalimat pertama bahasa Inggris kemudian mengganti kalimat kedua dengan bahasa Indonesia. Dari interview, mahasiswa melakukan code switching karena perubahasa situasi hadirnya orang ketiga. Dalam hal ini, dosen penguji adalah dosen bahasa Indonesia sehingga mahasiswa tersebut memberikan jawaban dengan bahasa Indonesia.

\section{Data 3}

Dosen : "The big problems of the students that you find. Apa yang kamu temukan. Ini kan nggak asal-asal kamu temukan kan?

Mahasiswa : "Problem nya, mereka masih belum bisa gitu mom speak English"

Dari percakapan diatas dianalisis bahwa penutur menggunakan jenis tag code switching yaitu alih kode terjadi ketika bilingual memasukkan ungkapan pendek dari Bahasa yang berbeda pada akhir ucapannya. Kata "kan" dalam kalimat "ini kan nggak asal-asal kamu temukan kan?" dan kata "nya" dalam kata "Problem nya". Kata "kan" dan "nya" merupakan bahasa yang berbeda dari bahasa Inggris dan bahasa Indonesia. Dari interview, dosen dan mahasiswa menambahkan kata-kata tersebut karena faktor habit atau kebiasaan dalam komunikasi sehari-hari.

\section{Kesimpulan}

Berdasarkan temuan penelitian, dapat disimpulkan bahwa code switching terjadi dalam tuturan selama proses seminar proposal. Jenis code switching yang terdapat dalam tuturan berdasarkan teori Romaine (2000) yaitu intra-sentential sebanyak 42 tuturan, inter-sentential sebanyak 26 tuturan dan terdapat 19 tuturan tag code switching. Faktor dosen dan mahasiswa melakukan code switching berdasarkan teori Chaer dan Agustina (2010) adalah karena perubahan situasi karena hadirnya orang ketiga, perubahan situasi dari formal ke informal atau sebaliknya, dan berubahnya topik pembicaraan. Dari hasil interview terdapat alasan lain mengapa mereka melakukan code switching yaitu karena bahasa Inggris bukan bahasa pertama mereka sehingga kurangnya kosakata bahasa Inggris membuat mereka sering menggunakan code switching didalam percakapannya. Selain itu karena faktor habit atau kebiasaan dalam percakapan sehari-hari.

\section{Daftar Rujukan}

Chaedar. 1998. Pengantar Sosiologi Bahasa. Bandung: Angkasa.

Chaer, Abdul dan Leoni Agustina. 2010. Sosiolinguistik. Jakarta: Rineka Cipta

Kridalaksana, Harimurti. 1984. Kamus Linguistik. Jakarta: Nusa Indah.

Miles \& Huberman. 1992. Analisis Data Kualitatif. Jakarta: UI-Press

Moleong, Lexy J. 2012. Metodologi Penelitian Kualitatif. Bandung: Remaja Rosdakarya

Nababan, PWJ. 1991. Sosiolinguistik Suatu Pengantar. Jakarta: Gramedia.

Rahmadani, Safitri. 2011. Alih Kode dan Campur Kode dalam Percakapan dalam Lingkungan Jurusan Bahasa Inggris di Universitas Indonesia. Depok.

Rezeki, Tri Indah. "Kontekstual Code Switching Dalam Seminar Proposal Program Studi Pendidikan Bahasa Inggris." Jurnal Serunai Bahasa Inggris 10.2 (2018): 1-7.

Romaine S. 2000. Language in Society. An Introduction to Sociolinguistics. Second Edition. New York: Oxford University Press

Sagala, Rakhmat Wahyudin, Tri Indah Rezeki, and Busmin Gurning. "Grammatical and Contextual Code Switching in the English Department Proposal Seminar." 3rd Annual International Seminar on Transformative Education and Educational Leadership (AISTEEL 2018). Atlantis Press, 2018.

Sugiyono. 2008. Metode Penelitian Kuantitatif, Kualitatif, dan $R \& D$. Bandung: Alfabeta

Sumarsono. 2004. Sosiolinguistik. Yogyakarta: Pustaka Pelajar 